ID_E N S Y O S

\title{
LA FRONTERA DEL AGUA: Una interpelación colectiva
}

Rosana Sommaruga, Norma Piazza, Javier Prieto y Graciela Baptista

Arquitectos y profesores en la Universidad de la Republica, Uruguay

\section{RESUMEN}

El presente artículo plantea una propuesta teórico-metodológica que se refiere a la conceptualización del paisaje en general y en particular a la noción de paisaje cultural surgida en el Programa de Investigación Paisaje y Espacio Público, del Instituto de Diseño de la Facultad de Arquitectura de la UDELAR.

Se articulan dos instancias de trabajo que consolidan y afianzan esta idea de paisaje. La investigación y publicación "La frontera del agua. El paisaje costero del Uruguay", presenta a través de una categorización específica, un área representativa de la identidad uruguaya como es la costa del Río de la Plata y Océano Atlántico.

En segunda instancia, un proyecto a realizar surge del anterior: "Por la frontera del agua, tour", presentación/exposición/taller, se refiere a la interpelación en los ámbitos locales de la propuesta realizada, reafirmando la idea de paisaje como construcción continua, colectiva y cultural.

Palabras clave: paisaje cultural, costa Uruguay, participación

ABSTRACT

The present article raises a theoretical-methodological proposal, which refers to the conception of landscapes in general, and particularly to the notion of cultural landscape, which emerged from the research program called Landscape and 


\section{ID E N A Y O S}

Public Space of the Design Institute of public University of the Uruguayan Republic.

It articulates two instances of work which consolidate and ensure this idea of landscape. The research and publication "The water's border, the landscape of Uruguayan coastline" presents through a specific categorization, a representative area of the Uruguayan identity such as the River Plate and Atlantic Ocean coastline.

From the previous one emerges another project to carry out. "Along the water's border, tour", presentation/exposition/workshop, refers to an appeal in the local ambit, to the realized proposal, reaffirming the idea of landscape as a continuous, collective and cultural construction.

Key words: cultural landscape, Uruguayan coastline, participation

\section{INTRODUCCIÓN}

El presente texto se refiere a una propuesta teórico metodológica que surge en el ámbito específico de investigación en Paisaje y Espacio Público del Instituto de Diseño de la Facultad de Arquitectura de la Universidad de la República (UDELAR), que materializa el estado del arte en este ámbito, en cuanto a la conceptualización del paisaje que hemos estado construyendo a lo largo de estos últimos años.

Estas reflexiones articulan también, a modo de rótula, dos instancias de este trayecto, refiriendo tanto a caminos recorridos, como a nuevos proyectos a desarrollar. De igual forma, todos ellos, van consolidando y afianzando esta idea de paisaje cultural que hoy se presenta en este espacio de intercambio. 
En primer lugar nos referiremos a la publicación "La frontera del agua. El paisaje costero del Uruguay", editada en el $2010^{1}$. Este proyecto de investigación y divulgación, es realizado por el Instituto de Diseño, en coordinación con otros servicios universitarios, y es fruto de la cooperación de la Consejería de Vivienda y Ordenación del Territorio de la Junta de Andalucía con el Ministerio de Vivienda, Ordenamiento Territorial y Medio Ambiente y la Intendencia Municipal de Montevideo. "La frontera del agua", tiene como objeto difundir un área rica, diversa y representativa de la identidad uruguaya, clave en su conformación territorial, como es la costa del Río de la Plata y del Océano Atlántico. Pretende ofrecer una mirada específica hacia este "espectáculo extraordinario", a la vez que convoca a otras interpretaciones disciplinares de este paisaje costero, reivindicando así la importancia y la concepción del paisaje como construcción colectiva y cultural.

En segundo lugar, presentaremos la idea de un segundo proyecto a realizar: "Por la frontera del agua, tour", presentación/exposición/taller. Éste surge del proyecto anterior y es el nuevo desafío que nos planteamos en el presente año, ya que se refiere a la interpelación en los ámbitos locales de la propuesta realizada en el libro, a través de diversas actividades de interacción y divulgación, dando cuenta de esta idea de paisaje como producción continua y construcción colectiva.

Es necesario entonces, referir brevemente a esta idea, cuál es el paisaje al que nos referimos.

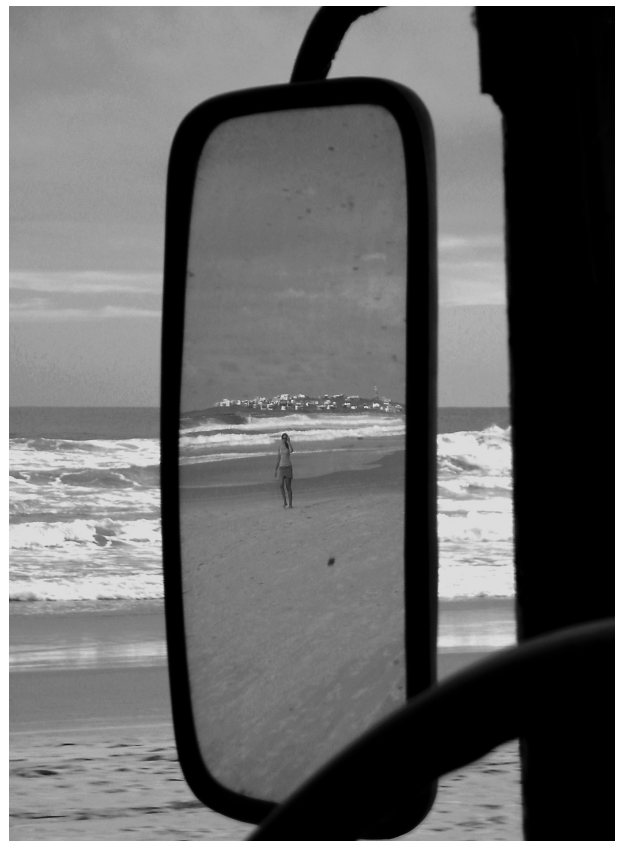

El paisaje es "una forma de mirar". Playa Sur, Cabo Polonio, Departamento de Rocha. Autor: Javier Prieto

${ }^{1}$ Publicación premiada con el Primer Premio en la categoría Teoría, Historia y Crítica de la Arquitectura y el Urbanismo en la XVII Bienal Panamericana de Arquitectura de Quito 2010. 


\section{ID E N A Y O S}

\section{NUESTRO PAISAJE}

El Consejero de Vivienda y Ordenación del Territorio andaluz, Juan Espadas Cejas, introducía el libro afirmando que "...el paisaje es la cultura territorial de un pueblo" (Espadas, 2010), ya que es la expresión formalizada de la gestión social sobre el territorio, a la vez que representación de los valores colectivos atribuidos al mismo.

Concordando con esta idea general, es preciso puntualizar nuevamente que la constelación de concepciones actuales del paisaje se ha ampliado, enriquecido y complejizado. Los múltiples alcances de su significado demuestran su carácter instrumental, ya que según la finalidad con que se percibe, la utilidad y práctica deviene de esta percepción. De lo anterior se deduce que el paisaje es hoy un rico espacio operativo, y que cada mirada según el interés y origen disciplinar, realiza una interpretación, una construcción específica.

No obstante, algunas hipótesis permiten comprender este resurgimiento disciplinar contemporáneo con sus múltiples acepciones. Algunas refieren a la situación cada vez más compleja y diversa de la realidad presente, que requiere nuevas miradas e interpretaciones a la hora de estudiar, proyectar y operar sobre el territorio. Otras se refieren a la revalorización creciente de los recursos naturales y culturales y consecuentemente a una visión crítica de la manipulación de los mismos. Una tercera hipótesis se basa en la consideración cada vez más consensuada del propio paisaje como recurso en los procesos de desarrollo territorial. Lejano de la concepción de escenario pasivo para su contemplación, se consolida la significación del paisaje como recurso social, económico y cultural, como promotor y calificador de desarrollos a nivel local y nacional (Sommaruga et al., 2010) ${ }^{2}$.

\footnotetext{
${ }^{2}$ Es importante señalar que a continuación los textos en cursiva que no tengan referencia expresa del autor, corresponden a extractos de distintos capítulos del libro "La frontera del agua. El paisaje costero del Uruguay" cuyos autores son Graciela Baptista, Gonzalo Macri, Norma Piazza, Javier Prieto, Victoria Rucks, Rosana Sommaruga e invitados externos al Programa de Investigación.
} 


\section{ID ENSAYOS}

Podemos aventurar que algunos planteamientos contemporáneos nos permiten de alguna manera explicitar estos supuestos integralmente. Estas interpretaciones se refieren a que los nuevos modos de interacción del hombre con el territorio, recentran las relaciones entre naturaleza y cultura, y, consecuentemente las nuevas formas de conceptualizar esta relación.

En este sentido, Ábalos plantea que ya no hay naturaleza, al menos como se entendía antes de los modernos, la parte salvaje y virginal del 'ahí afuera'. Ahí afuera hay un conglomerado, la herencia moderna, un mundo donde aparecen mezclados $y$ envueltos naturaleza $y$ artificio por un mundo vectorial $y$ telemático: el jardín moderno (Ábalos, 2005).

Por otra parte, Silvestri y Aliata plantean que el paisaje, como noción contingente, condensa los modos culturales modernos de acercamiento al mundo natural. Estos autores afirman que la noción de paisaje ha sido indagada nuevamente como camino alternativo para pensar las relaciones entre los artefactos humanos y la naturaleza (Silvestri y Aliata, 2001).

En este marco de apreciaciones que refieren a las relaciones emergentes entre naturaleza y cultura y sin renegar de las nociones tradicionales que refieren a la percepción, a la representación de componentes naturales y a su apreciación en su aspecto artístico, hemos intentado construir una mirada más amplia y compleja. Esta noción de paisaje refiere básicamente a su cualidad cultural, a la imagen y sus atributos específicos de la visualidad y a la intencionalidad intrínseca de este concepto para operar en la arquitectura y el territorio.

Decíamos entonces, hemos intentado promover una idea de paisaje que se funda en una construcción colectiva. Una idea de paisaje que, centrada en una forma de "mirar", incorpore otras visiones, que integre la diversidad $y$ complejidad No obstante, algunas concepciones se han afianzado con mayor 


\section{ID E N A Y O S}

fuerza y convicción en nuestras prácticas y en nuestro hacer; nos referimos a la consideración del paisaje cultural y al paisaje como materia de proyecto.

\section{El paisaje cultural. El paisaje como materia de proyecto}

Tomemos como base, con algunas aclaraciones, el concepto de paisaje cultural expuesto en la Convención de Patrimonio Mundial de la Unesco de 1998. Éste se refiere a que estos paisajes son ilustrativos de la evolución de la sociedad humana y del uso del espacio a lo largo del tiempo, y poseen la capacidad de hacer visibles los elementos culturales esenciales y distintivos de una región.

Si partimos de esta acepción en el sentido más amplio de la idea, podríamos afirmar sin temor a equivocarnos que podemos considerar a todo el territorio como paisaje cultural, ya que aún la valoración del paisaje natural es un acto cultural.

Es posible que algunos de estos paisajes, expresen de forma más evidente el atributo de la representatividad de una región geográfica y culturalmente definida. No obstante, si somos consecuentes con el concepto general, y precisos con la definición, todo el territorio puede ser considerado paisaje cultural.

Sin embargo, es conveniente referirnos a la raíz del propio concepto de paisaje. $\mathrm{Al}$ respecto, el profesor Le Dantec, afirmaba que es el observador que hace del país un paisaje... y aclara: Etimológicamente en las lenguas latinas, tenemos "país" o paese y después-agio. "País", que es la palabra que hasta entonces existía, es completada por un sufijo que viene del latín (-actun) que designa un acto, una intencionalidad, por lo tanto, una mirada llevada voluntariamente hacia algo (Le Dantec, 2003). 
ID_ENSAYOS

De lo anterior, si convenimos que el paisaje es una forma de mirar el territorio, podríamos afirmar también, que la expresión "paisaje cultural" es redundante dado que el propio concepto de paisaje lleva de forma intrínseca la cualidad cultural del mismo.

No obstante, esta idea asegura la incorporación de los imaginarios colectivos, la puesta en valor de los valores escénicos y de los elementos referenciales como atributos que forman parte de la cultura urbana y territorial. Podemos convenir que la carga semántica atribuida a la expresión "paisaje cultural" y las prácticas y modos de acción asociados a esta expresión es potente y operativa a la hora de proponer e intervenir. ${ }^{3}$

Partiendo entonces de la idea del paisaje como construcción cultural y de la intencionalidad inherente al concepto mismo en cuanto a la interpretación, representación e intervención en el territorio, surge claramente su dimensión proyectual.

El paisaje constituye recurso y oportunidad de acción. Deja su rol pasivo tradicional de escena o fondo y se constituye en "material de construcción", en un "sistema activo", en el lugar donde lo natural y lo artificial componen una nueva materialidad (Galofaro, 2003).

El paisaje no es solo objeto de protección y preservación, puede ser también sujeto de nueva propuesta y reinvención. El paisaje es sujeto de proyecto.

De todo lo anterior podemos concluir que, el paisaje es "una forma de mirar", y el proyecto de paisaje "una forma de activar" el territorio. Que este último, como todo proceso proyectual, constituye un proceso racional-intuitivo de mediación

${ }^{3}$ En las últimas décadas, esta idea de paisaje cultural ha promovido importantes intervenciones de revalorización de parques urbanos e industriales en desuso, y en particular la generación de parques patrimoniales como instrumento de planificación y proyecto. 


\section{ID E N A Y O S}

de imaginarios y que específicamente convoca la sensibilidad con el entorno y la revalorización de nuestro hábitat a través de nuevas relaciones entre naturaleza y cultura. Como todo proceso de proyecto, propende a una mejora del hábitat y de la calidad de vida constituyéndose en oportunidad para el desarrollo.

Podemos afirmar entonces que el proyecto del paisaje contemporáneo se configura como un proyecto de reconciliación con el territorio.

\section{El paisaje como recurso}

Las características y cualidades anteriores dan cuenta de la consideración cada vez más presente de la condición de recurso del paisaje, tanto como recurso de identidad y pertenencia, recurso para la creación y la acción, ó incluso como "mercancía". Cualquiera de estas aproximaciones implica aprovechamiento, beneficios y valor económico que se relaciona con su abundancia o escasez.

No obstante es conveniente puntualizar que suscribimos la consideración del paisaje como "recurso" cuando su valorización apunta al crecimiento de la existencia humana en todas sus manifestaciones y dimensiones.

Una de las actividades donde se manifiesta más claramente esta condición de recurso del paisaje es la actividad turística. $Y$ esta propia condición hace que el paisaje y el turismo planteen una relación dialéctica en la que se producen afectaciones y modificaciones mutuas.

Sin embargo "... el turismo no resulta en sí mismo una perturbación ni una amenaza: es un problema de dosis y de gestión". (Gómez Aguilera, 2007). 


\section{ID ENSAYOS}

Por tanto, esta relación infiere al concepto de sustentabilidad, ya que este no solo refiere al crecimiento económico sino al desarrollo integral y a la satisfacción de las necesidades y el bienestar de una comunidad.

Este concepto plantea un desarrollo vinculado a capacidades, conocimientos, posibilidades y oportunidades para todos, que busca articular los recursos naturales con los culturales y con las posibles rentas, sin romper el equilibrio de los sistemas físicos, naturales y sociales.

La idea entonces, no es promover paisajes turísticos sino turismo en los paisajes.

Incluso cabe precisar, determinados tipos de turismo. Turismos compatibles con el recurso que le da origen, donde se aprovecha adecuadamente las cualidades del lugar y su cultura, promoviendo transformaciones con sentido positivo.

Concluyendo y sin pretender definir un modelo de turismo sostenible universal, la Organización Mundial del Turismo plantea tres premisas básicas: el uso óptimo de los recursos ambientales, manteniendo los procesos ecológicos esenciales y ayudando a conservar los recursos naturales y la diversidad biológica; el respeto a la autenticidad sociocultural de las comunidades anfitrionas, conservando sus activos culturales vivos y sus valores tradicionales para así contribuir al entendimiento y a la tolerancia interculturales; y la viabilidad de las actividades económicas a largo plazo, que reporten a todos los agentes beneficios socio-económicos suficientes y bien distribuidos.

\section{UNA INTERPRETACION DEL PAISAJE CULTURAL}

En la publicación, "La frontera del agua. El paisaje costero del Uruguay" planteamos estas ideas generales que han guiado los últimos trabajos del 
Programa. Por otra parte, esta área rica y frágil como es la costa del Río de la Plata y Océano Atlántico, es apropiada y oportuna para ensayar esta interpretación "no ortodoxa" de paisaje cultural dada su diversidad y complejidad. "...ciudades y puertos albergan diversas infraestructuras productivas y urbanizaciones balnearias. Praderas, paisajes serranos, campos dunares, humedales salinos y el caudal de ríos y arroyos se encuentran con diversidad de paisajes modelados por la mano del hombre" (Ehrlich, 2010).

Y precisamente, por estas cualidades y calidades, frágiles y complejas, es que se torna indispensable una interpretación paisajística específica que complemente otras formas de analizar e intervenir en el territorio.

Conjugar las múltiples demandas sociales que convergen en la "frontera del agua" no es tarea sencilla. La variedad de actores e intereses en juego o la importancia de integrar distintas miradas disciplinares que logren dar cuenta de su alta complejidad lo evidencian. La dificultad de la tarea, sin embargo, no la hace menos necesaria (Colacce, 2010).

La frontera del agua entonces, plantea 3 capítulos necesarios y complementarios.

Primeramente se desarrolla nuestra visión específica sobre el paisaje, que involucra una interpretación amplia de la noción de paisaje, la consideración del paisaje como recurso y la acción de valoración de este paisaje dado su cualidad de construcción colectiva y cultural.

En segundo lugar, se presentan diversas miradas y aportes disciplinares que evidencian, a través de estudios específicos, los principales elementos del fenosistema del área costera.

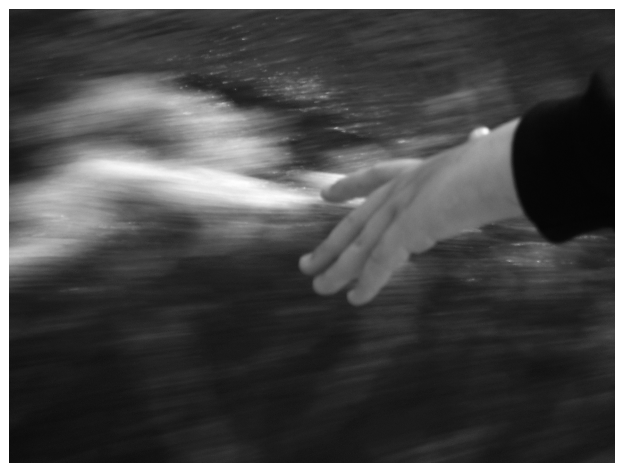

El proyecto de paisaje es "una forma de activar". Río de la Plata, Departamento de Montevideo. Autor: Javier Prieto 


\section{ID ENSAYOS}

Por último, se presentan veintinueve ejemplos de paisajes costeros, agrupados en ocho tipos de paisaje. Esta categorización pretende ilustrar los aspectos característicos y representativos de esta situación de frontera agua-tierra.

\section{La condición del lugar, agua y paisaje}

Decíamos también que esta área frontera otorga una significación particular a la relación entre agua y paisaje y que esta relación adquiere singular importancia en los imaginarios colectivos contemporáneos, ya que la valoración del paisaje costero es fruto de un largo proceso de construcción cultural.

Es innegable la impronta del agua en el paisaje a la vez que reconocida su trascendencia como cuestión cultural contemporánea. Como huella o como componente fundamental, por presencia pretérita o por ausencia, por escasez o por abundancia, el agua condiciona y caracteriza el paisaje así como detenta un conjunto de roles asociados de gran trascendencia en la construcción de la noción de paisaje cultural. Sea como atractor territorial, como soporte de actividades o como elemento destacado del paisaje para su contemplación, el paisaje costero constituye uno de los tipos de paisaje más apreciados y codiciados.

Por tanto podemos convenir que los paisajes del agua constituyen paisajes culturales por excelencia, ya que han provocado la acción humana para el usufructo de este recurso, originando imágenes y representaciones culturales a la vez (Mata Olmo y Fernández Muñoz, 2008).

\section{Los paisajes culturales en la costa uruguaya}

Consecuentemente con el objetivo de la publicación en cuanto a la difusión de los paisajes costeros del Uruguay, una categorización de los mismos nos permite presentar y estructurar este conocimiento de forma ordenada. Por otra parte, como planteábamos en la misma, la propia clasificación es un acto de 
valoración, reforzando así la idea de intencionalidad intrínseca al concepto de paisaje ya que describir es analizar y clasificar es proponer (Sabaté, 2011) ${ }^{4}$.

En este marco, y desde nuestra mirada paisajística, planteamos una categorización que ponga en valor aquellos aspectos destacados y singulares del paisaje costero que lo convierten en área única. A diferencia de las tipología territoriales tradicionales, la clasificación propuesta pondera determinadas representaciones del espacio costero y refiere tanto a ámbitos como a recorridos, tanto a lo físico y a lo geográfico como a la percepción y a la actividad.

Esta categorización no pretende constituirse en genérica, sino que, plantea una "tipología" abierta e inacabada que, seleccionando aspectos significativos, permite referir al mismo ejemplo desde diversas miradas. No pretende clasificar todo el universo de posibilidades sino que, por el contrario, promueve detenerse en los atributos identificatorios y singulares del ejemplo.

Por su parte, el agua comporta diversos roles definitorios, contribuyendo de esta forma a la construcción de la clasificación. ¿Por qué esta categorización, compleja y multidimensional?

Primeramente, porque permite ahondar en las características propias que infiere el concepto paisaje, en la especificidad que lo distingue de otras visiones disciplinares como son la relación entre naturaleza-cultura, las apropiaciones y los imaginarios, el movimiento, las mutaciones de la escena, entre otros.

A su vez, esta clasificación temática posibilita reflexionar sobre los espacios de interfase disciplinar, esto es, los espacios de frontera donde confluyen distintos saberes, intimando nuevamente a precisar lo propio de la mirada paisajística

${ }^{4}$ Conceptos vertidos por el profesor Joaquín Sabaté en el Seminario "Paisajes culturales, proyecto territorial y desarrollo local", realizado en la Facultad de Arquitectura de la Universidad de la República de Montevideo, Uruguay los días 2 y 3 de febrero de 2011.

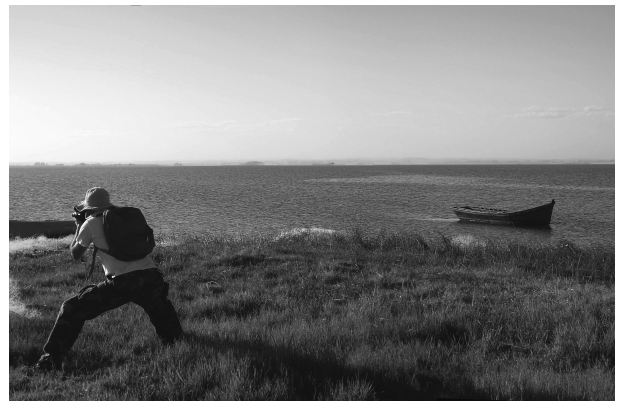

De paisajes turísticos a turismo en los paisajes Laguna de Rocha, Departamento de Rocha Autor: Javier Prieto 


\section{ID ENSAYOS}

en referencia a los otros enfoques. En segundo lugar, porque se refiere a aspectos representativos del paisaje costero uruguayo que lo singularizan tanto por su carácter y contundencia, como por sus valores ambientales y estéticos. Por último, esta categorización da cuenta de la impronta indiscutible de las actividades turísticas en el paisaje costero. Profundizar en este conocimiento en sus distintas manifestaciones, permite orientar los destinos turísticos y coadyuva a establecer las adecuadas relaciones turismo-paisaje, en cuanto aptitudes y vocaciones del lugar, detectando fortalezas, así como fragilidades y amenazas.

Decíamos en referencia a la clasificación de la Unesco que la categorización propuesta se inscribe, en términos generales, en la definición de los paisajes evolutivos, ya que todos los ejemplos responden a esta situación ${ }^{5}$.

"Si bien algunos tipos de paisaje propuestos pueden identificarse con las restantes categorías -paisajes asociativos y paisajes diseñados- e incluso algunos ejemplos pueden identificarse con otras categorías de bienes, como los centros históricos o rutas patrimoniales, la interpretación que promovemos intenta referir a una visión más compleja del territorio, en todo de acuerdo a lo explicitado en la propia definición general de paisaje cultural en cuanto a que "comprende una gran variedad de manifestaciones de la interacción entre la humanidad y su entorno natural” (UNESCO, 2007).

Ocho categorías reúnen los ejemplos seleccionados ilustrando las características valoradas y representativas del área. Las seis primeras mantiene el patrón de presentación, mientras que las dos últimas se exponen particularmente para evidenciar las características propias del tipo. A continuación se transcriben sintéticamente los ocho tipos de paisaje definidos:

${ }^{5}$ La Convención de Patrimonio Mundial define estos paisajes como aquellos que han evolucionado orgánicamente y son "fruto de una exigencia originariamente social, económica, administrativa y/o paisajes reflejan este proceso evolutivo en su forma y en su composición". 
ID_ENSAYOS

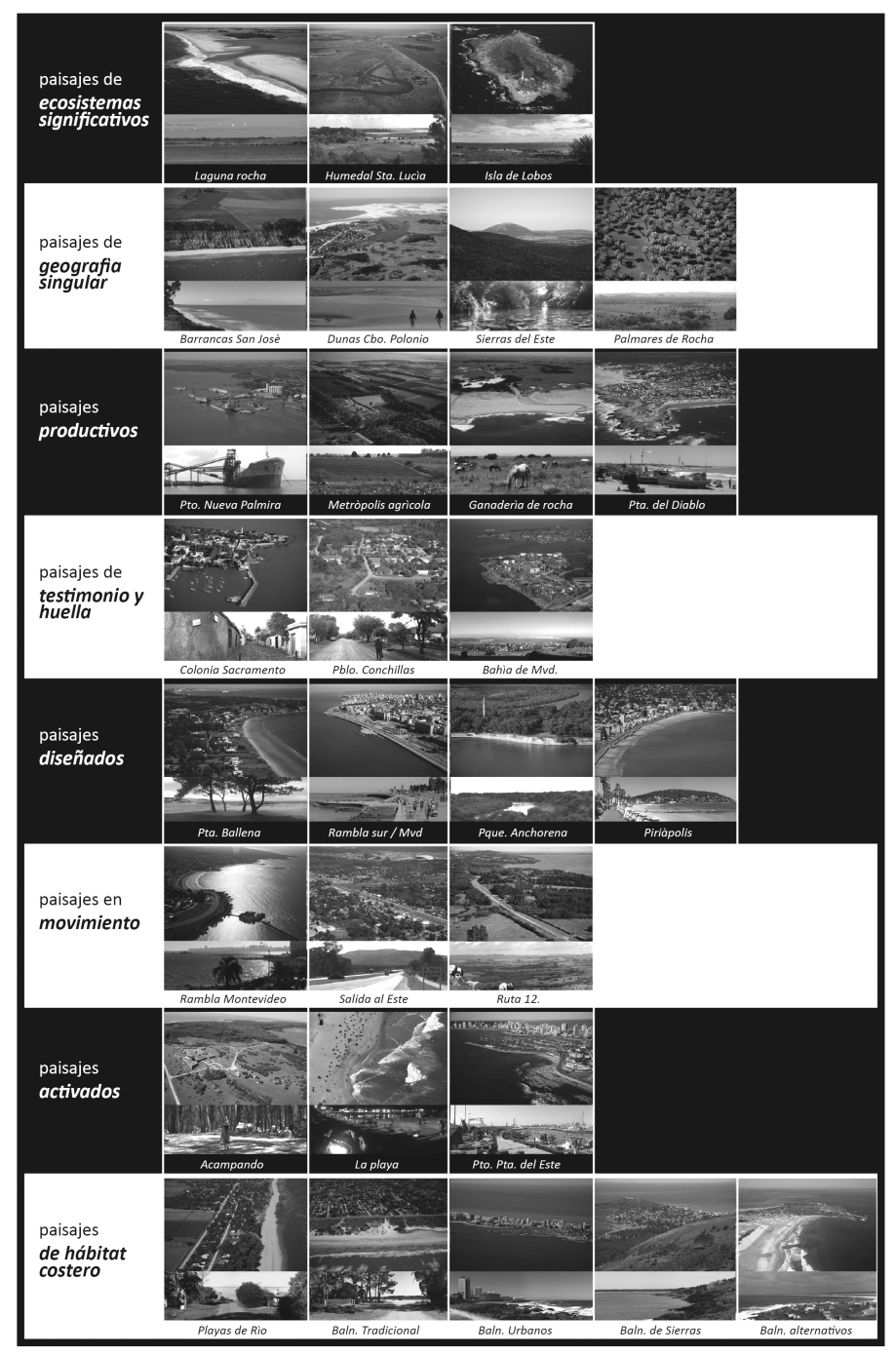

Categorización / clasificación / valoración de paisajes costeros Autor: Javier Prieto 


\section{ID E N A Y O S}

\section{A. Paisajes de ecosistemas significativos. El agua como sustento de biodiversidad}

Es aquel paisaje donde la percepción de las distintas manifestaciones de la biodiversidad, en un ambiente predominantemente natural, es el factor determinante $y$ calificatorio. Se valoran y se aprecian esencialmente los ecosistemas naturales y el agua se presenta primordialmente como sustento de biodiversidad.

Decíamos que este tipo de paisaje evidencia en mayor medida que otros, la realidad ambiental del espacio, sus relaciones y su salud, por tanto se articula estrechamente con la visión ecológica. No obstante, es necesario precisar las diferencias entre los conceptos de paisaje y ambiente ${ }^{6}$, ya que el paisaje no es un aspecto del ambiente ni "es reductible a un ecosistema" (Roger, 1998). A pesar de que estas diferencias parten de la propia génesis de estos conceptos y que ambas visiones refieren integralmente a los aspectos naturales $y$ culturales de un territorio, estas visiones presentan un posicionamiento diferencial que, según el profesor Alain Roger, “... infiere la relación entre ciencia y arte, entre análisis cientifico y estético" (Roger, 1998).

Por su parte, estos paisajes pueden considerarse los más representativos de la promoción institucional "Uruguay natural" y se adecúan a lo que se denomina turismo de naturaleza, o ecoturismo. Sin embargo, la apreciación de los valores ambientales no tiene una equivalencia directa con la valoración estética y cultural. Ejemplo de esto son los criterios de selección del Sistema Nacional de Áreas Protegidas que en primera instancia no consideran la preservación del paisaje desde el punto de vista perceptual y sociocultural.

\footnotetext{
${ }^{6}$ Recordemos que el paisaje occidental surge como invención pictórica en el siglo xv mientras que el ambiente es un concepto científico reciente, de origen ecológico, desarrollado fundamentalmente en la segunda mitad del siglo $x x$.
} 


\section{ID E N A Y O S}

De esta gran diversidad de paisajes se seleccionan algunos ejemplos significativos y representativos de nuestra costa. Algunos de ellos como la Laguna de Rocha y los Humedales del Santa Lucia, se caracterizan porque en su biodiversidad general, las poblaciones diversas de aves aportan al paisaje una destacada singularidad visual y acústica. En otros casos como la Isla de Lobos, el número de individuos de una o dos especies predominantes, son determinantes en la función del ecosistema, a la vez que definitorios en la caracterización de la escena.

\section{B. Paisajes de geografía singular. El agua como agente modelador}

Es aquel paisaje donde los elementos del soporte geográfico y/o las coberturas vegetales dominantes brindan los principales atributos visuales que 10 conforman y caracterizan. Se estima lo distintivo de situaciones geomorfológicas singulares y en muchos de estos casos se identifica el rol del agua como agente modelador.

La relación entre geografía y paisaje es indudable dado que el soporte geográfico brinda los elementos esenciales que caracterizan al paisaje manifestando así lo fenomenológico del territorio, su fisonomía. No obstante, la distancia entre las dos nociones también es indiscutible. Al respecto, el profesor Daniel Vidart expresa: "La geografía es la ciencia de los paisajes. Pero el paisaje que estudian los geógrafos no es el de los pintores ni el de los escritores, subjetivizado por las axiologías estéticas. El paisaje geográfico es objetivo, accesible a los sentidos, sustantivo, tridimensional...” (Vidart, 1967).

Por su parte, este segundo tipo comparte con el primero la representación de la promoción "Uruguay Natural". En ambos casos, la actividad turística deberá desarrollarse con modos compatibles y sinérgicos con el recurso. Al ecoturismo se le agrega el turismo deportivo y el turismo escénico y modalidades especializadas con cualidades peculiares. 
En este grupo se seleccionan paisajes singulares caracterizados por los elementos del soporte geográfico y las coberturas vegetales dominantes. Es el caso de los barrancos del departamento de San José, las estribaciones de la Cuchilla grande que llegan a la costa como las Sierras del este, las dunas de Cabo Polonio y Valizas y los palmares de Rocha. Algunos ejemplos evidencian la acción del agua desde épocas geológicas como la principal fuerza modeladora del paisaje. En otros, las configuraciones vegetales priman en el carácter de la escena y le confieren su principal expresividad. En cualquiera de ellos, la percepción de situaciones casi "prístinas", cada vez menos frecuentes, otorga hoy su mayor valía como paisaje cultural.

\section{Paisajes productivos. El agua como factor de desarrollo productivo}

El paisaje productivo es aquel donde los tipos de producción son determinantes en la modelación del territorio y hacen visibles las formas de apropiación cultural del mismo, definiendo el carácter de la escena. Se valoran las actividades productivas con impronta en el paisaje visual y cultural. El agua es el componente fundamental como factor de desarrollo productivo.

"Las alteraciones que experimenta y continua experimentando la superficie de la tierra no son otra cosa que las consecuencias indirectas y visibles de aquellos procedimientos y medios que sirven a los fines de la cultura material, es decir, de las necesidades materiales del hombre, concernientes a su alimentación, vestimenta, desplazamiento de un lado a otro, vale decir, a los objetivos de la economía humana" (Vidart, 1967). Como plantea el profesor Vidart, históricamente la antropización del territorio, ha tenido como objeto el usufructo de los recursos, la adaptación al medio y la construcción del hábitat.

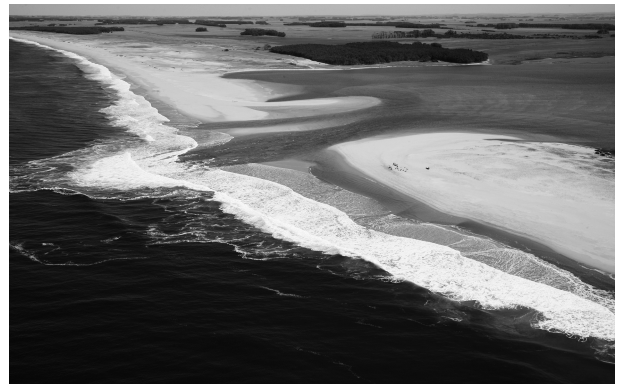

Laguna de Rocha: Escenas de Biodiversidad. Paisaje de Ecosistema Significativo. Departamento de Rocha. Autor: Antonio Ruik 


\section{ID ENSAYOS}

$\mathrm{Si}$ bien todas estas apropiaciones económicas del territorio pueden considerarse paisajes productivos, en esta categoría ponemos centro en aquellas que son determinantes para una conformación espacial y escénica distintiva, a la vez que constituyen paisajes prototípicos en el desarrollo de nuestro país. Este tipo de paisajes ha propiciado tipos de turismo específicos asociados a la actividad, turismo de rutas productivas, turismo rural, gastronómico, de tradiciones culturales, entre otros.

En este marco se seleccionan cuatro ejemplos diversos: El paisaje portuario de Nueva Palmira, las praderas del departamento de Rocha como soporte de la ganadería extensiva a borde de costa, los paisajes agrícolas de la producción intensiva hortofrutícola del Montevideo metropolitano y Punta del Diablo como paisaje paradigmático que manifiesta la tendencia actual de transformación de un pueblo de pescadores.

\section{Paisajes de testimonio y huellas. El agua como estructurador del territorio}

Es aquel paisaje que, fiel representante de la noción de paisaje cultural, evidencia claramente determinados momentos paradigmáticos de construcción urbana y territorial o explicita las complejidades de las "multicapas" generadas en los procesos históricos de conformación del territorio. Este paisaje manifiesta a través del feno-sistema los elementos culturales identitarios, a modo de palimpsesto. El agua cumple en general el rol de estructurador del asentamiento urbano y territorial.

Decíamos que esta categoría incluye distintas escalas y se manifiesta “... en trazas $y$ ordenaciones urbanas y rurales, en arquitecturas, en elementos conmemorativos, incluso en todos aquellos hechos -con expresión espacial- o eventos -permanentes o contingentes- que refieran a un legado, costumbre $o$ tradición, constituyéndose en patrimonio intangible. Ciudades, barrios, complejos industriales, actualmente en funcionamiento o en reconversión, 


\section{ID ENSAYOS}

estructuras edilicias, hechos históricos que dejan su huella o señal en la localidad de referencia, comidas tradicionales, fiestas populares, apropiaciones. Estos representan los patrones adoptados a lo largo del tiempo o en un momento dado de la historia y la evolución de los valores culturales de una sociedad. El reto mayor de este tipo de paisaje es su gestión y administración, dado que la preservación de este patrimonio paisajista debe coadyuvar a no perder la autenticidad de sus valores a la vez que integrarse a las dinámicas territoriales sin recurrir a operaciones turísticas de "congelamiento" escenográfico.

Los ejemplos seleccionados constituyen un grupo diverso. Conservan las marcas de su conformación y se diferencian en su evolución a lo largo del tiempo. El pueblo "ingles" de Conchillas ilustra su etapa original de construcción y luego de un período de letargo se enfrenta a importantes desafíos de desarrollo hacia el futuro. Colonia de Sacramento, detenta la categorización de patrimonio mundial evocando una imagen primigenia rehabilitada para el turismo internacional. Por último, la Bahía de Montevideo como umbral de nuestra ciudad, brinda un paisaje complejo y representativo de la capital del país así como conforma un anfiteatro de su proceso de conformación.

\section{H. Paisajes diseñados. El agua en el diseño del paisaje}

Tomando como antecedente la categoría Unesco, el paisaje diseñado es aquel que es creado intencionalmente por el hombre, claramente definido $y$ construido por razones funcionales y estéticas, con referencia a modelos tanto paisajísticos como urbanísticos. En este caso, se ponderarán los modelos paisajísticos. Se identifican y valoran los modelos aplicados desde el punto de vista del proyecto de paisaje. El agua es el componente fundamental y detonador del diseño.

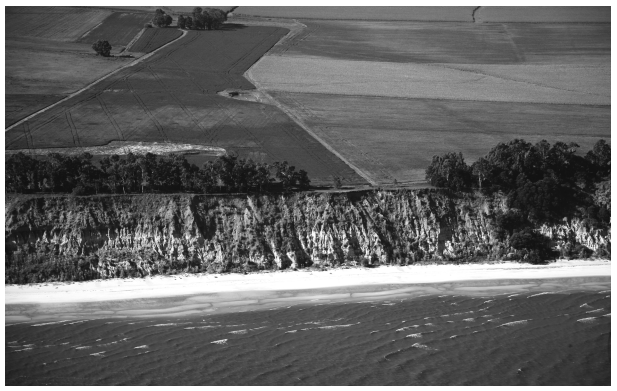

Barrancas de San José: Miradores naturales del Plata. Paisaje de geografía singular. Departamento de San José. Autor: Antonio Ruik 


\section{ID ENSAYOS}

En el contexto actual, donde el resurgimiento del paisaje como disciplina proyectual es un hecho indiscutido, esta visión contemporánea se construye hoy de modo proactivo, desplegando su condición como materia de proyecto. El diseño del paisaje retoma lo "propositivo" del concepto proyecto como lo "expresivo" del concepto diseño. En la búsqueda de nuevas formas de acercamiento entre naturaleza y cultura el diseño del paisaje es más "... el proyecto de un sitio, que el proyecto de un programa" (Portela, 2002), con las particularidades de su época, de su cultura y de su lugar. Por tanto, Los paisajes diseñados o "creados intencionalmente" se constituyen como una oferta específica independiente o complementaria a otras ofertas turísticas. Son paisajes calificados con el valor agregado específico del diseño y por eso se constituyen en atractivo para un turismo cultural con intereses especiales.

Los ejemplos seleccionados constituyen hitos significativos de esta categoría de paisaje en el espacio costero. La fuerte identidad de la naturaleza del sitio, provocadora de la concepción de la idea, conjuga con los imaginarios culturales de la época. El modelo urbanístico explícito se convierte en modelo paisajístico referente. Las escenas construidas por el diseñador de paisaje, en algunos casos fruto de empujes solitarios y visiones temerarias y en otros, producto de políticas territoriales públicas y privadas, se convierten con el uso y el tiempo, en símbolos de nuestra identidad nacional en cuanto a una particular forma de apropiación de la frontera tierra-agua. Los ejemplos seleccionados son Punta Ballena, el Arboretum y Portezuelo, la Rambla Sur, la estancia presidencial Anchorena y la ciudad de Piriápolis.

\section{Paisajes en movimiento. El agua como fondo escénico}

Es aquel paisaje donde la percepción del viajero a través de las distintas velocidades del espacio temporal es el factor determinante para su representación. Referencia la accesibilidad al paisaje condicionada por la 


\section{ID ENSAYOS}

velocidad y los distintos tipos de desplazamientos. El agua se manifiesta fundamentalmente como fondo escénico.

Las infraestructuras viales... toman cada día más relevancia en nuestras vidas y por tanto en la representación y construcción cultural del paisaje. Uno de los aspectos sustanciales de esta experiencia genuina que es la travesía por el paisaje es la conciencia de su condición temporal. ... Como "miradores dinámicos" -auténticas experiencias paisajísticas- permiten el andar como práctica social para aproximarse a un sinfín de situaciones y paisajes diversos. En su doble condición, permiten el acceso al paisaje escondido como constituyen en sí mismas una configuración paisajística.

En las últimas décadas se ha propiciado crecientemente el turismo de itinerario temático, promocionando determinados recursos del territorio, culturales, de producción, gastronómicos y otros. No obstante, paradójicamente, las actuales propician la pérdida progresiva de la calidad de andar y habitar la ruta en tanto viajero. Nos preguntábamos entonces: Ante una movilidad motorizada cada vez mayor, ¿Someteremos la apreciación del paisaje en el andar? ¿Perderemos paulatinamente la capacidad de relacionarnos con el territorio en condición de viajeros? ¿Reduciremos progresivamente la práctica del paisaje en ruta al tránsito a altas velocidades de automóvil? Los paisajes seleccionados remiten a distintas percepciones y velocidades de apreciación.

Los ejemplos muestran la variedad de manifestaciones de esta categoría de paisaje. Entornos urbanos por excelencia como La Rambla de Montevideo, la condición metropolitana mutando hacia el espacio balneario en el sistema Giannattasio-Interbalnearia, y el predominio de la escena natural como factor preponderante en la Ruta panorámica número 12. 
ID_ENSAYOS

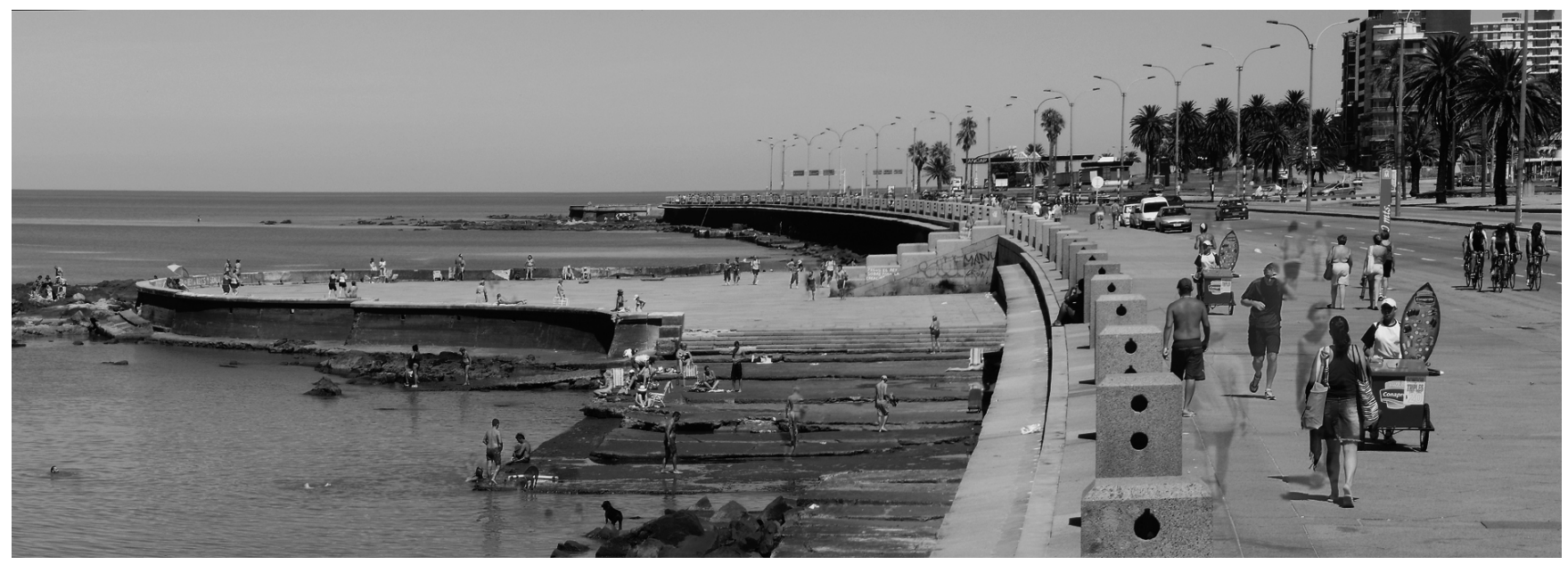

La Rambla Sur: Balcón al "Río como Mar". Paisaje diseñado. Departamento de Montevideo Autor: Javier Prieto

\section{J. Paisajes activados. El agua como componente fundamental de la} actividad

Es aquel paisaje donde la impronta de la actividad humana en el territorio es el factor fundamental y determinante de la escena. Las apropiaciones del lugar a través de las prácticas sociales constituyen este paisaje. La presencia de actividades sociales y sus consecuentes espacios temporales son la causa fundamental de su mutabilidad. El agua constituye el factor fundamental para que el paisaje se "active".. ...

Es evidente que una de las dimensiones que constituye aspecto fundamental en la configuración del paisaje es la dimensión temporal. Desde las variaciones diarias, estacionales y climáticas generales, que incorporamos naturalmente en nuestros ciclos de vida, hasta los acontecimientos paisajísticos, lo efímero, 


\section{ID ENSAYOS}

el evento como experiencia, aportan a nuestro devenir y a nuestra experimentación, percepción y construcción cultural del paisaje. El tiempo como noción abstracta, se hace evidente en las múltiples configuraciones que nos ofrece la escena, amenizando la cualidad de permanencia estructural que detenta un territorio. $Y$ deciamos también que entre las múltiples prácticas posibles de apropiación y activación del espacio, en las prácticas "fugaces" parece radicar la genuina representación de las apropiaciones colectivas del espacio. Acciones o escenas aparecen y se esfuman a pesar de permanecer en los imaginarios colectivos como referentes sociales y culturales ineludibles. Por su parte, los paisajes sociales se relacionan directamente con las corrientes denominadas de turismo cultural. Sin embargo, “... las manifestaciones culturales no escapan al fetichismo de lo simbólico ni al olfato comercial" (Bonet, 2008). El turismo cultural mal orientado puede provocar la banalización del producto en detrimento de la autenticidad, de los aspectos identitarios y de significación social.

En este marco tan amplio y diverso que nos permite esta categoría es difícil seleccionar ejemplos representativos. No obstante, se eligen tres temas significativos en cuanto a las "apropiaciones paisajisticas" de los espacios costeros. Estos son el habitar transitoriamente el espacio costero a través de los campamentos, las actividades estivales de playa y las dinámicas propias de los espacios portuarios. En el marco de ejemplos se hará mención especial al Parque Nacional Santa Teresa, la fiesta de Yemanyà que se celebra cada dos de febrero o las playas de nuestro país y la actividad portuaria del Puerto de Punta del Este. 


\section{ID E N A Y O S}

\section{K. Paisajes de hábitat costero. El agua como atractor del ocio activo y pasivo}

Es aquel paisaje donde los modos de habitación generados para la temporada de descanso y turística, y las actividades relacionadas al ocio activo y pasivo con relación a la playa y al mar configuran su característica visible más determinante. Se identifican y se valoran los diferentes tipos culturales de hábitat, modos de vida y actividades asociadas. Constituirse como atractor del ocio activo y pasivo es el rol principal del agua.

Nuevas articulaciones entre lo urbano y la naturaleza, surgen en nuestro país a fines del siglo xix y principios del $x x$, producto de cambios culturales, sociales y económicos. "Un nuevo tipo de asentamiento urbano basado en una valorización de elementos naturales hasta entonces desaprovechados: las playas" (Vidart, 2001). Estos asentamientos, comúnmente denominados "pueblos balneario", primeramente se relacionan con las playas de río, para asociarse posterior y definitivamente a la costa oceánica. La "cultura de la playa" se instala en el imaginario colectivo, que otorga a esta área de frontera el valor social y cultural del lugar preeminente de escape de la vida diaria, de prácticas y experiencias de verdadera libertad.

La interfase agua-tierra constituye el principal atractor y las distintas configuraciones de hábitat, ponderan de forma diferencial aspectos determinantes del borde. Estas apropiaciones se diferencian en las relaciones con el soporte geográfico, las infraestructuras y estructuración urbana y periurbana, las tipomorfologías y la valoración diferencial de la accesibilidad, los usos y relación con los recursos naturales.

Sin pretender ahondar en los procesos históricos y urbanos de la costa uruguaya en esta última categoría procuramos centrar la mira en la diversidad de paisajes generados por la interacción del hábitat construido y las 
características territoriales, naturales y culturales. En ella no se seleccionan lugares específicos sino modelos de apropiaciones que se remite a comportamientos tipo desarrollados a lo largo de importantes sectores de la faja costera.

Por último, como planteábamos al inicio, si hacemos énfasis en el carácter instrumental que detenta el término paisaje, cada mirada, según la finalidad con que se percibe, realizará una construcción específica del concepto. No obstante, la promoción de interpretaciones abiertas que posibiliten distintas profundizaciones y nuevos alcances de esta cuestión del paisaje permitirá seguir ahondando en esta visión disciplinar, consolidando su especificidad.

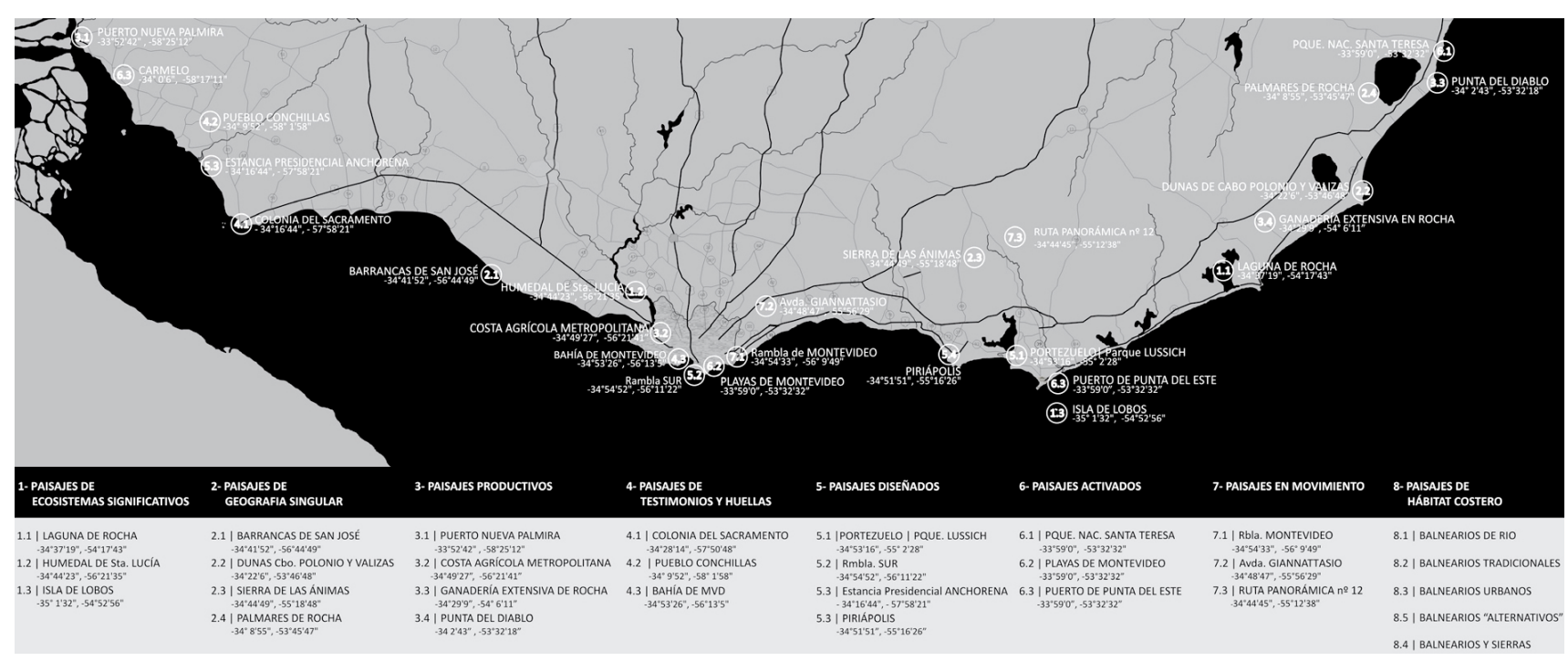

Plano general de paisajes seleccionados 


\section{ID INVESTIGACIONES}

\section{POR LA FRONTERA DEL AGUA, TOUR}

El segundo proyecto que nos referiremos es un proyecto de divulgación y extensión que surge a partir de la investigación presentada anteriormente.

Partiendo de la concepción del paisaje como construcción colectiva y cultural, surge la idea de interpelar las valoraciones realizadas sobre el paisaje costero uruguayo, en los ámbitos locales con las comunidades involucradas.

Este nuevo emprendimiento que proponemos pretende multiplicar el acceso a la información e influir positivamente en actores y habitantes, estimulando el reconocimiento de los recursos de cada localidad y la importancia del paisaje desde sus múltiples visiones. Procuramos así contribuir a la sensibilización y concientización sobre el paisaje como patrimonio y capital territorial, al mismo tiempo que enriquecer interpretaciones académicas promoviendo procesos de construcción continua y conjunta del conocimiento.

El material gráfico obtenido en el desarrollo de la investigación ha sido rico y abundante, sobrepasando los límites necesarios para el formato del libro. Aprovechando esta circunstancia se propone una exposición fotográfica acompañada de textos que mantienen el hilo conductor planteado, siendo ésta a nuestro entender, un medio adecuado y eficiente para acceder a distintos tipos y cantidad de público a la vez que un atractor de actividad.

\section{Del paisaje al ciudadano, del ciudadano al paisaje}

Con la aprobación de la Ley de Ordenamiento Territorial y Desarrollo Sostenible (Ley $n^{\circ}$ 18.308) en el 2008 como Marco Regulador General se establecen entre otros, los derechos y deberes territoriales de las personas, consagrando su participación en la elaboración de los instrumentos de ordenamiento territorial y el acceso a la información sobre el territorio. Por otro 


\section{ID_INVESTIGACIONES}

lado, también se definen instrumentos especiales que permitirían a partir de estudios identificar y determinar regímenes de protección posible para el paisaje.

Así, información y participación se transforman en la clave de una buena gobernanza democrática. Buscando colaborar en este proceso se plantea una propuesta de divulgación activa, una muestra itinerante como herramienta de difusión que ayude a comprender, valorar, discutir y generar opinión. La muestra se convierte también en excusa para proponer otras actividades que permitan recoger la información y las valoraciones locales.

Parece obvio que la identificación de los valores simbólicos e identitarios del paisaje representa un reto harto complicado, con una dosis de incertidumbre considerable y con una manifiesta multiplicidad de opiniones y perspectivas legítimas. Por todo ello, la gestión del paisaje representa, hoy por hoy, un tema de elevada complejidad.

La participación pública se concibe en el ámbito no exclusivo de la integración de las opiniones de la ciudadanía sobre el paisaje. Es necesaria una apertura de miras en sentido amplio. Ello significa mostrar las decisiones y dudas metodológicas a la población, invitándolos a integrarse en un proceso de coproducción del conocimiento mismo del paisaje y de su evaluación (de San Eugenio Vela, 2006).

Nos proponemos junto con los actores de estos paisajes verificar la representatividad de los ejemplos seleccionados, evaluando así el trabajo realizado y la metodología aplicada.

Por otro lado también proponemos promover la participación de la población en la construcción de este conocimiento con la identificación de eventos y sitios 


\section{ID_INVESTIGACIONES}

paisajísticos, singulares o cotidianos, representativos de sus comunidades, que no han sido seleccionados en el trabajo. Sitios o recorridos considerados como bienes públicos, patrimonio del conjunto de la sociedad. Para esto incluimos en el proyecto, dinámicas que impulsen el aporte de quienes concurran.

Esta posibilidad de difusión y colección de aportes de los ciudadanos, convierte estas instancias de la muestra en una primera fase, base de una agenda abierta de trabajos del equipo de investigación, que apuntan a la elaboración del catálogo de paisajes del Uruguay como insumo imprescindible del proyecto de territorio.

La oportunidad de un desarrollo estructural y cualitativo solo será ofrecida por el reconocimiento de lo propio e identitario (Santos, 1996).

\section{El tour}

Se prevé implicar en el diseño del tour, los sitios y regiones departamentales involucradas en el paisaje costero uruguayo. Cada destino constituirá una etapa del mismo, cumplimentando en cada uno de ellos las tres fases del proyecto: presentación, exposición y ágora-taller.

Complementariamente al evento inaugural donde se realiza la presentación del proyecto, se prevé implementar actividades interactivas que conjuguen las distintas percepciones referidas a las características visuales y a la carga cultural y simbólica de los paisajes presentados.

La exposición fotográfica se corresponderá con la estructura del libro. Esta será acompañada de textos sintéticos que estructuran la muestra y guían la mirada a través de las distintas escalas y los puntos de vista abordados. Durante la permanencia de la exposición en la localidad se invitará a los visitantes a participar identificando en un mapa, hitos, lugares y eventos que se consideren patrimonio paisajístico local, así como recorridos de interés. Desde el punto de 


\section{ID_INVESTIGACIONES}

vista metodológico, esta geo-referencia colectiva de los valores de la comunidad permitirá evidenciar, datos relevantes de las manifestaciones culturales locales, así como situaciones de deterioro o pérdidas a considerar.

Se prevé culminar esta etapa en una jornada de intercambio en modalidad de taller que materialice finalmente, en la cartografía del paisaje local, el producto de la construcción participativa del paisaje cultural.

En síntesis con este proyecto pretendemos profundizar procesos ya iniciados y detonar nuevas propuestas. Entre los resultados esperados que involucran al equipo de trabajo se encuentran la consolidación de la integración de las prácticas de participación en la investigación, la evaluación del trabajo realizado y específicamente de la metodología propuesta, el conocimiento de valoraciones locales y la incorporación de nuevos conocimientos.

El alcance principal de la actividad para la población, se manifiesta en la posibilidad de incorporar una mirada diferente a sus paisajes de vida iniciando un proceso de valoración consciente de lo que para ellos es cotidiano, en el conocimiento y valoración de otros paisajes de nuestro territorio, así como también la profundización de los procesos de participación en los ámbitos locales.

\section{ALGUNAS CERTEZAS Y NUEVOS DESAFíos EN LOS PROCESOS DE CONSOLIDACIÓN DISCIPLINAR DEL PAISAJE}

El reconocimiento y consolidación disciplinar del paisaje en el concierto contemporáneo de saberes es un proceso creciente y sostenido. Los trabajos presentados, constituyen dos etapas de un mismo trayecto que ha transitado el Programa de Investigación: Paisaje y Espacio público en los últimos años, referentes al estudio, conceptualización y propuesta sobre el paisaje. Este trayecto ha sido orientado por una serie de conceptos guía entre los que se 


\section{ID_INVESTIGACIONES}

destacan la consideración del paisaje como constructo cultural y el paisaje como materia de proyecto.

En este marco, la mayoría de los estudios realizados han procurado potenciar la cualidad instrumental de la mirada paisajística a la hora de la intervención en procesos de desarrollo territorial. Los mismos pretenden evidenciar el carácter operativo de la disciplina paisajística tanto en proyectos de investigación y divulgación como en proyectos de difusión y extensión.

Esta "forma de mirar" el territorio, de analizarlo e interpretarlo, puede constituirse en una herramienta en el camino del conocimiento de nuestro paisaje, esto es, un nuevo conocimiento a valorar, o bien puede detonar nuevos procesos de planificación y desarrollo territorial que tengan su elemento vertebrador en esta mirada integradora.

La consideración del paisaje como recurso territorial, genera nuevas oportunidades de proyecto y gestión del territorio que involucra tanto las profundizaciones de la especificidad en gabinete, como la convocatoria a distintos enfoques y a diversos actores. Proyectos de revalorización y generación de paisajes culturales a develar y profundizar, a convenir con la comunidad dado que el paisaje es una construcción cultural y colectiva. Este proceso de consolidación disciplinar requiere también de la exploración de nuevas prácticas y métodos instrumentales, de la generación de masa crítica y el ensayo de nuevas interpretaciones.

La coyuntura actual nacional nos plantea nuevos desafíos en diversos niveles y dimensiones de acción. Las nuevas ofertas de enseñanza específicas de la

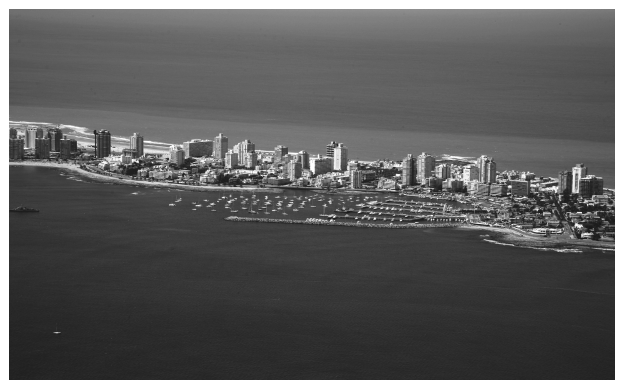

Punta Del Este: Balneario urbano significativo. Paisaje de hábitat costero. Departamento de Maldonado. Autor: Antonio Ruik 


\section{ID I NVESTIG AC I O NES}

disciplina del paisaje ${ }^{7}$, como la construcción de políticas de ordenación del territorio bajo la égida de la nueva Ley de Ordenamiento Territorial y Desarrollo Sostenible - que consideren efectivamente al paisaje de forma operativa desde su dimensión proyectual en todos sus términos-, son dos ejemplos fehacientes de la necesidad de su profundización.

La línea de trabajo que planteamos para su puesta en consideración, se presenta como un encuadre versátil que permite encauzar diferentes proyectos desde una actitud proactiva y pretende contribuir al proceso de consolidación disciplinar del paisaje, con una propuesta de construcción colectiva integradora tanto de legos como de actores y pobladores del territorio.

\section{BIBLIOGRAFÍA}

ÁBALOS, Iñaki (2005). Atlas pintoresco. Vol. 1: el observatorio. Madrid, G. G.

AUGÉ, Marc (1998). El viaje imposible. El turismo y sus imágenes. Madrid, Gedisa.

COLACCE Carlos (2010). Prólogo del Ministerio de Vivienda Ordenamiento Territorial y Medio Ambiente. En SOMMARUGA, Rosana coord. (et.al) (2010) La frontera del agua. El paisaje costero del Uruguay. Montevideo, UDELAR, Facultad de Arquitectura, Instituto de Diseño- IMM-MVOTMA-Junta de Andalucía. (pág. 7)

\footnotetext{
${ }^{7}$ Nos referimos a las nuevas ofertas educativas de la Universidad de la Republica, que se están implementando en los últimos años como la Licenciatura en Diseño de Paisaje dictada desde el año 2008 en el departamento de Maldonado y el Diplomado en Proyecto de Paisaje cuyo primer módulo fue dictado en el año 2010 en la Facultad de Arquitectura, Montevideo. No obstante lo anterior, la demanda de diversos cursos de esta especificidad se han requerido e implementado tanto en ofertas de grado como en la propio Facultad de Arquitectura y en otros servicios Universitarios como cursos y módulos opcionales en las ofertas de posgrado de nuestra casa de estudios.
} 


\section{ID_INVESTIGACIONES}

EHRLICH Ricardo (2010). Prólogo de la Intendencia Municipal de Montevideo. En SOMMARUGA, Rosana coord. (et al) (2010) La frontera del agua. El paisaje costero del Uruguay. Montevideo, UDELAR, Facultad de Arquitectura, Instituto de Diseño- IMMMVOTMA-Junta de Andalucía (pág. 8)

ESPADAS Juan (2010). Prólogo del Consejero de Vivienda y Ordenación del Territorio. En SOMMARUGA, Rosana coord. (et al) (2010) La frontera del agua. El paisaje costero del Uruguay. Montevideo, UDELAR, Facultad de Arquitectura, Instituto de Diseño- IMMMVOTMA-Junta de Andalucía (pág. 9)

EVENO, Claude y CLÉMENT, Gilles (1998). El Jardín Planetario. Montevideo, Trilce.

GALOFARO, Luca (2003). Artscapes. El arte como aproximación al paisaje contemporáneo. Barcelona, G. G.

NOGUÉ, Joan (2007). (ed.). La construcción social del paisaje. Madrid, Biblioteca Nueva, S.L.

ROGER, Alain (1997). Court traité du paysage. París, Gallimard.

SANTOS, Milton (1996). De la totalidad al lugar. Barcelona, Oikos Tau,

SILVESTRI, Graciela y ALIATA, Fernando (2001). El paisaje como cifra de armonía. Buenos Aires, Nueva Visión.

SOMMARUGA, Rosana coord.(et al) (2010) La frontera del agua. El paisaje costero del Uruguay. Montevideo, UDELAR, Facultad de Arquitectura, Instituto de Diseño- IMMMVOTMA-Junta de Andalucía.

TOLEDO, Alejandro (2006). Agua, hombre y paisaje. Ciudad de México, INE-SEMARNAT.

VIDART, Daniel (1967). El paisaje uruguayo. Montevideo, Alfa.

Documentos electrónicos:

DE SAN EUGENIO VELA, Jordi. (2006). La gestión del paisaje desde la comunicación. Un estudio de caso: el Observatorio del Paisaje de Cataluña. Disponible en: www.hapaxmedia.net/ibercom/pdf/deSanEugenioVelaJordi.pdf 


\section{ID INVESTIGACIONES}

GÓMEZ AGUILERA, Fernando. (2007). Paisaje de las visitadas islas, turismo y territorio. Cuadernos del sureste. $\quad N^{0} 10$. Disponible en: <http://www.lineae.com/cuadernos/pdfs/numero10/paisajedelasvisitadas.pdf>.

MATA OLMO, Rafael y FERNÁNDEZ MUÑOZ, Santiago.(2009). Paisajes y patrimonios culturales del agua. Andalucía, Fundación Nueva Cultura del Agua. Disponible en: $<$ http://www.andalucia.ccoo.es/comunes/temp/recursos/2/71779.pdf>.

SABATÉ, Joaquín (2004) De la preservación del patrimonio a la ordenación del paisaje. Urbano, Año 7. NN 010. <http://www.redalyc.uaemex.mx/redalyc/pdf/198/19871009.pdf>.

SAUER, Carl. O. (1925).La morfología del paisaje [traducción de Guillermo Castro H.] University of California Publications in Geography. Vol. 2, № 2. California, Universidad de California (http://www.colorado.edu/geography/giw/sauer-co/LaMorforlogiaDelPaisaje.doc).

UNESCO (2007).Conferencia General, 29a reunión. Informe sobre las actividades del Comité Intergubernamental para la protección del patrimonio mundial cultural y natural. Disponible en: http://unesdoc.unesco.org/images/0010/001089/1089385.pdf

VIDART, Daniel (2001) El paisaje uruguayo: naturaleza y cultura. En Comisión Paisaje y Ambiente de la Sociedad de Arquitectos del Uruguay. Ciclo paisaje y

ZOIDO NARANJO, Florencio. Los paisajes del agua en Andalucía. Andalucía: GIEST. <http://www.upo.es/ghf/giest/documentos/paisaje/Zoido_paisajesdelaguaenandalucia.pdf>.

\section{Documentos inéditos}

INSTITUTO DE DISEÑO et al.(2006) Pautas para el Ordenamiento Paisajístico de la Rambla de Montevideo. Montevideo, IMM-UdelaR/Facultad de Arquitectura, (en prensa)

PIAZZA, Norma (2008). Articulaciones paisaje-turismo. La cualidad de recurso del paisaje, el turismo como proyecto de desarrollo sustentable. Monografía inédita. Montevideo.Facultad de Arquitectura.

LE DANTEC, Jean Pierre (2003). La invención del paisaje en Occidente. Desde la Roma antigua hasta nuestros días. Conferencia inédita en seminario: Paisaje y ciudad - Museo de Artes Visuales - Facultad de Arquitectura - Universidad de la Republica- Uruguay. 


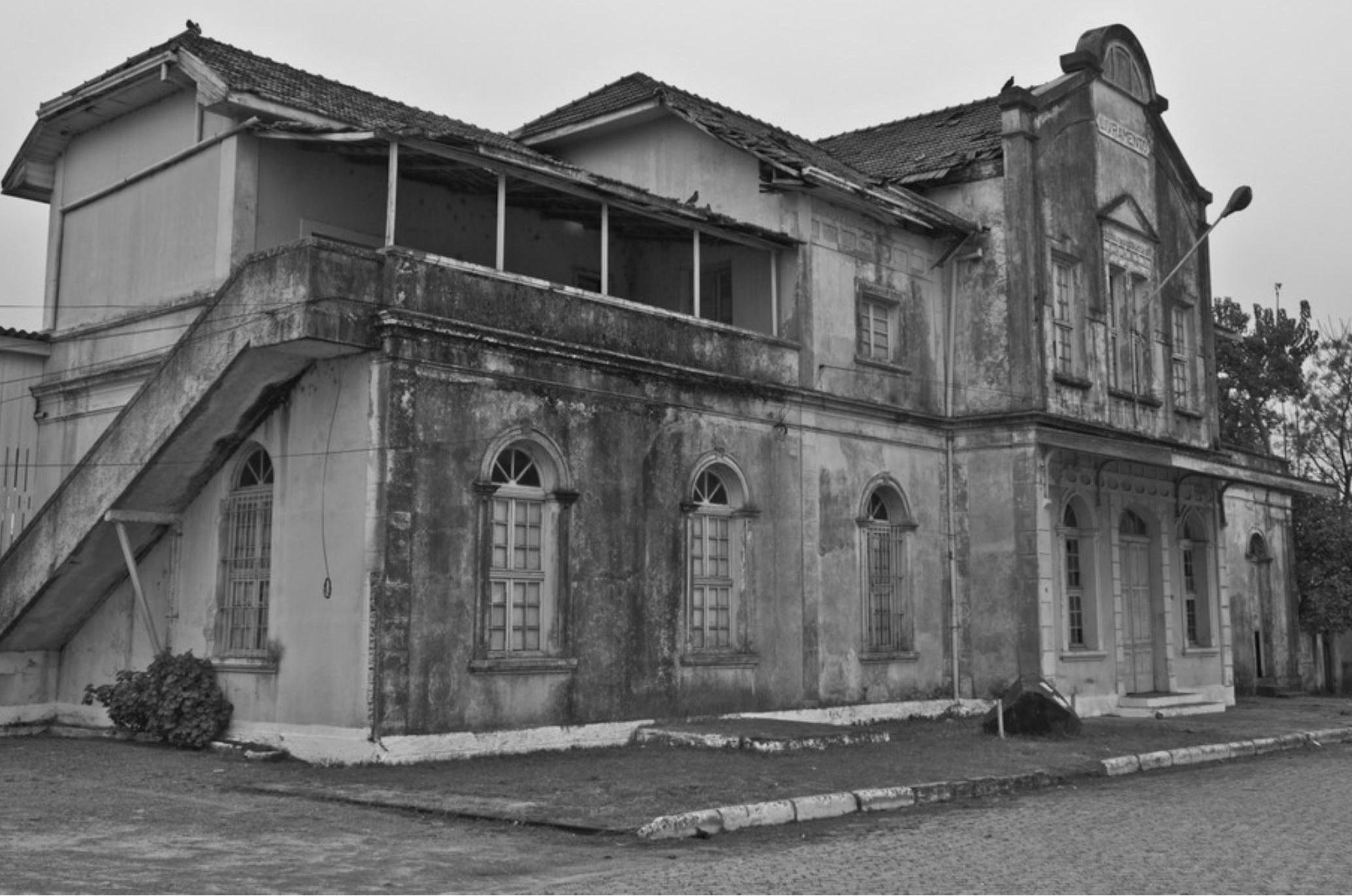

Livramento. Fuente: foto cedida por el Servicio de Medios Audiovisuales Facultad de

Arquitectura, autora Danaé Latchinian 